\title{
Reseña de La Bola. Revista de divulgación de la Historia Review: La Bola. Revista de divulgación de la Historia
}

\author{
Clementina Battcock *
}

\begin{abstract}
* Doctora en Historia la UNAM, especializándose en estudios sobre las crónicas novohispanas de tradición indígena novohispana y andina. Desde 2013 es Profesora Investigadora de la Dirección de Estudios Históricos del Instituto Nacional de Antropología e Historia. Es miembro del Sistema Nacional de Investigadores, nivel I, del CONACyT. Ha publicado en revistas de alcance mundial radicadas en Alemania, Argentina, Brasil, España, EEUU, Italia, México, Japón, Francia y Perú. Producto en gran medida de la suma de esfuerzos para un diálogo académico internacional, ha coordinado los siguientes libros colectivos: Acerca de la (Des)memoria y su construcción en Mesoamérica y los Andes, en coordinación con Sergio Botta (2015); Mudables representaciones. El indio en la Nueva España a través de crónicas, impresos y manuscritos, en coordinación con Berenise Bravo Rubio (2017), y Lo múltiple y lo singular. Diversidad de perspectivas en las crónicas de la Nueva España, en coordinación con Luis Barjau (2018). Es profesora de la Escuela Nacional de Antropología e Historia del INAH, en donde desarrolla la línea de investigación titulada Los antiguos barrios de México-Tenochtitlan: Representaciones simbólicas, espacio y sociabilidad; del Colegio de Historia en la Facultad de Filosofia y Letras de la UNAM, donde es actual titular de la asignatura Mesoamérica. Asimismo, es profesora del Posgrado en Estudios Mesoamericanos, UNAM. Recientemente fue publicada su investigación posdoctoral en el Centro de Investigaciones en América Latina y el Caribe de la UNAM, titulada La Guerra entre Incas y Chancas. Relatos, sentidos e interpretaciones (2018), además de un libro en coautoría con Silvia Limón Olvera titulado El imaginario colectivo en Mesoamérica. Representaciones y símbolos en el Altiplano Central Mexicano (2018). Correo electrónico cbattcock@yahoo.com.ar

(i) http://orcid.org/0000-0002-9899-1214
\end{abstract}

Historial editorial

Recibido: 04-julio-2019

Aceptado: 30-agosto-2019

Publicado: 23-septiembre-2019

ISSN-e: $2594-2956$ 


\section{Reseña de La Bola. Revista de divulgación de la Historia}

Iniciar un nuevo proyecto editorial no es poca cosa, es más, en estas realidades/temporalidades de la humanidad, resulta una apuesta/emprendimiento que podríamos denominar "de valientes". Así la presentación en sociedad de La Bola. Revista de divulgación de la Historia, se advierte el notable ímpetu que tienen los jóvenes historiadores que conforman el Comité Editorial, los cuales generaron un espacio de divulgación de la Historia. Salta a la vista que detrás de ese ejercicio existe una reflexión atinada y consciente sobre el quehacer académico en estos tiempos, sus problemas, dificultades y contradicciones, en las cuales estamos inmersos los hijos de Clío.

Curiosamente, fue hace unos pocos meses que participé en la presentación de otra revista impulsada por jóvenes colegas de la Escuela Nacional de Antropología e Historia e insistí, así como lo reitero ahora, en valorar este tipo de publicaciones digitales, no sólo por su formato amigable, flexible y didáctico, sino también por apreciar que en estos tiempos en los que lo inmediato es primordial, debemos buscar la necesidad de detenernos y pensar qué hay detrás de una nueva publicación, sea libro o en este caso una revista electrónica de divulgación de la Historia. Me permito hacer este comentario porque detrás de cada proyecto editorial hay mucho trabajo, esfuerzo y horas de labor de todo tipo: académica pero también personal. Como ustedes podrán observar al entrar a este primer número de esta revista, hay un proyecto académico que genera una serie de expectativas para nuestra comunidad académica, a la vez que plasma un interés en la producción y difusión del conocimiento. Esto no es poca cosa en los tiempos en que nos toca afrontar una realidad poco alentadora, y un panorama 
complejo en donde mucho de lo colectivo pasa casi desapercibido; en cambio este proyecto manifiesta un interés, una preocupación loable, básica y crítica sobre el futuro que nos espera en las ciencias sociales. Quizás a manera de hipótesis podemos pensar a esta nueva publicación como parte de una cadena generacional y hereditaria de otras revistas que han surgido en distintos espacios institucionales: creo que esto no es un detalle al azar, sino que es toda una postura/posicionamiento ideológico y pragmático. Apostar a la difusión/divulgación creo que es un camino más que interesante, pues se interrelaciona con una postura transgeneracional que implica buscar constantemente extender y diseminar, a través del tiempo y del espacio, una noticia, una idea, costumbres, idiomas, modas, entre otros, para un público ávido de conocer.

Desde que se me hizo la invitación para presentar este primer número titulado Las armas de la nación. De la revolución a la lucha contra el crimen organizado, me aproximé a conocer la plataforma y sus contenidos, encontrándome con una fotografía del zócalo capitalino lleno de gente joven; y en el centro de la escena una tanqueta militar que impone los hechos que estaban aconteciendo.

Así el volumen se presenta como un mosaico de textos con múltiples miradas y abordajes en los que convergen ejes de discusión sobre dinámicas políticas, sociales y culturales; desde perspectivas que presentan al lector la profundidad de la riqueza histórica y las problemáticas a las que se enfrentan para ser explicadas.

Como intentaré trazar seguidamente, y disculpándome en no describir a detalle cada sección porque la idea es que se acerquen y lean la totalidad de la revista, los textos que componen este número exploran desde distintas miradas la distancia temporal/espacial que deshace los 
pasados, y que con ello cimienta sobre ellos las elaboraciones políticas y culturales presentes pero demarcadas y constantes en el tiempo. Así la labor histórica se perfila a proponer reflexiones sobre cómo entre el espacio y el tiempo tienen lugar distintas confluencias cuya proximidad explicativa depende en buena medida de las miradas, intervenciones y mediaciones del participante/interlocutor.

Desde sus cinco secciones: Legajos, Contrapunto, Multimedia, Almanaque y Gacetilla, nos topamos con una estratégica forma de presentar el esqueleto de la revista.

Desde la entrada denominada Editorial se formula una exposición breve, concreta y ordenada del comité editorial, explicando las motivaciones y disposición del volumen: las fuerzas armadas en México para contextualizar el surgimiento y debate de la Guardia Nacional. Seguidamente pasamos a la sección de Legajo, integrada por tres textos: De defensores de la Constitución a soldados de la nación: las fuerzas armadas en México entre I9I4 y 1945 de Daniel Ramírez Guzmán, Las fuerzas armadas mexicanas, de la Segunda Guerra Mundial a la Guerra Sucia, de Pedro Celis y Edwin Alberto Álvarez, y el último estudio De la Oscuridad a la luz: las fuerzas del orden en los últimos 40 años de César Valdés. Debo agregar que los tres estudios cuentan con una serie de fotografías que acompañan los casos presentados y que resultan interesantes para nuevos análisis y dialogan con la narrativa de cada texto. Me explico: las imágenes no son de carácter ilustrativo, sino que son otra narrativa,

218 podríamos pensarlas en paralelo, que registran/relatan/revelan otras formas y ángulos de la historia.

La siguiente sección es Contrapunto y presenta un texto a cargo de Alberto O. Barreto Berrecil que expone bajo el título de ¿Qué nos dice hoy en día la cinta "El prisionero I3"? mismo que incluye una reseña sobre 
dicho filme y los ejes problemáticos que son abordados a través de los personajes y en el propio guión. Debo agregar que me resultó interesante la intervención técnica que se subraya sobre el sonido y su "vanguardia visual", entre otras cosas.

Posteriormente se despliega, cuasi podríamos decir como ruptura dentro de la revista, dos entrevistas grabadas bajo la nominación: Las armas de la nación de Carlos Fazio y Bernardo Ibarrola. Este acto intencional de los editores de registrar en este formato las entrevistas, considero que funciona no solo como arista entre sección y sección sino aprovechan este tipo de plataforma tecnológica para incorporar a un público que le interesa y es consumidor de este soporte.

Almanaque está integrado por tres particulares y disímiles textos: $\mathrm{La}$ triste noche de Hernán Cortés, El gobierno constitucional anuncia el Programa de la Reforma y La algarada estudiantil de 1968. Debo declarar que esta sección me pareció sumamente original y que cada uno de ellos cierre con Para saber mas... es una herramienta seductora e inteligente, ya que despierta un interés y proporciona una bibliografía accesible y pertinente.

Como cierre, esta publicación nos ofrece la sección de Gacetilla donde se acercan novedades o noticias de nuevos libros. En este primer número se reseñan Io obras publicadas entre 2018 y 2019. Asimismo, se comentan críticamente tres exposiciones que lamentablemente ya no se pueden visitar porque culminaron el 30 de junio. Sin embargo, creo que es muy buena idea dar este tipo de información y difundir este tipo de actividades. También se reseñan cuatro programas de radio que abonan a la difusión de la Historia. 
Por último, debo declarar que lo que me atrae de este primer número es la cantidad de preguntas que disparan hacia los retos teóricos y metodológicos que exponen los distintos autores en sus artículos y las secciones con estilos de escritura y variedad narrativas. La Bola. Revista de divulgación de la Historia es una publicación electrónica desenvuelta que roza la experimentación y que reta a los modos tradicionales de difundir la Historia. Sólo me queda agregar que festejo y agradezco este esfuerzo editorial que permite acercarnos a los lectores, legos o no, a entablar un diálogo que permite establecer cruces, producir concurrencias propias/colectivas, y con ello reflexionar sobre la forma de relatar/entender/difundir la Historia invitándonos a trascender lo digital para reflexionar sobre nuestra realidad, invitación que en nuestro actual contexto político y social mundial no es poca cosa.

\section{Referencias}

Las armas de la nación. De la Revolución a la lucha contra el crimen organizado. (2019). La Bola. Revista de Divulgación de la Historia, I(I). Recuperado de: http://labola.com.mx/home-I/

Este artículo se publica bajo una licencia de Creative Commons Reconocimiento-NoComercial 4.0
Internacional, y puede ser usados gratuitamente para fines no comerciales, dando los créditos a los
autores y a la revista.

